\title{
Differential regulation of cytokine-induced major histocompatibility complex class II expression and nitric oxide release in rat microglia and astrocytes by effectors of tyrosine kinase, protein kinase $\mathrm{C}$, and cAMP
}

\author{
Ronald P. Hellendall ${ }^{\text {a, }}$, Jenny P.-Y. Ting a,b \\ ${ }^{a}$ Lineberger Comprehensive Cancer Center, University of North Carolina, Chapel Hill, NC 27599-7295, USA \\ ${ }^{\mathrm{b}}$ Department of Microbiology / Immunology, School of Medicine, CB \# 7295, University of North Carolina, Chapel Hill, NC 27599-7295, USA
}

Received 24 May 1996; revised 20 September 1996; accepted 24 September 1996

\begin{abstract}
Two glial cell populations of the CNS, astrocytes and microglia, were examined for expression of two immunologically important molecules, MHC class II and nitric oxide (NO), following treatment with cytokines. IFN- $\gamma$ induced both molecules in microglia at substantially higher levels than astrocytes. The addition of TNF- $\alpha$ to IFN- $\gamma$ elevated class II expression and NO in both cells. Genistein, an inhibitor of tyrosine kinases, and calphostin, an inhibitor of protein kinase C, diminished cytokine induction of class II MHC and NO in both glial populations. Forskolin was most effective in inhibiting class II MHC expression, but had little inhibitory effect on NO production. These results indicate microglia are more effective than astrocytes in producing cell-associated and secreted immune mediators in response to IFN- $\gamma$ and or TNF- $\alpha$ and multiple parallel, but distinct, signaling events are required for cytokine induced class II MHC or NO production.
\end{abstract}

Keywords: Ia; Nitric oxide synthase; Microglia; Astroglia; Neuroimmunology

\section{Introduction}

Glial cells of the central nervous system (CNS) express a number of molecules important in mediating responses to alterations in the internal environment of the brain. Interferon-gamma (IFN- $\gamma$ ) is a powerful inducer of a number of genes whose products are critical for an immune response. The regulation of class II MHC (Ia) antigens and nitric oxide (NO) expression in the brain is particularly interesting since these molecules can greatly alter immune reactivity and may lead to pathology. The goals of this report are to (a) directly compare the relative capacity for two glial populations in the brain, microglia and astrocytes, to express Ia and NO; and (b) to examine the intracellular signaling pathways that lead to Ia expression and NO release in these cells.

\footnotetext{
Abbreviations: IFN- $\gamma$, interferon-gamma; TNF- $\alpha$, tumor necrosis factor-alpha; I $+\mathrm{T}$, IFN- $\gamma$ plus TNF- $\alpha$

* Corresponding author. Tel.: + 1-919-9662662; fax: + 1-919-9663015; e-mail: rph3681@email.unc.edu
}

Ia antigens form a complex with foreign peptides on the cells surface and serve as a ligand for the T-cell receptor resulting in T-cell activation (Cresswell, 1990). Ia antigen expression has been used as a sensitive marker to localize immune reactive cells in the CNS since most Ia bearing cells found in other nonlymphoid tissue exhibit the ability to activate $\mathrm{T}$ lymphocytes. The nature, location, and function of Ia positive $\left(\mathrm{Ia}^{+}\right)$cells in the CNS may be particularly relevant to immune regulation since neural tissue is generally exempt from T-cell immune surveillance and lacks conventional lymphatic drainage. A subpopulation of CNS cells express MHC class II and have been shown to present antigen to $\mathrm{T}$ cells in a MHC-restricted fashion (Fontana et al., 1984; Sasaki et al., 1989). These cells include astrocytes and microglia: whereas astrocytes can be induced to express class II in vitro and have been found of regions of CNS pathology, microglia appear to be the main immune effector of the brain (Hayes et al., 1987).

IFN- $\gamma$ is a potent transcriptional inducer of Ia antigen on human and rodent astrocytes and microglia (Fierz et al., 1985; Frei et al., 1987; Pulver et al., 1987; Suzumura et al., 1987; Ting et al., 1981). A cascade of phosphorylation 
events follow ligand binding to the IFN- $\gamma$ receptor leading to elevated transcriptional activity from the class II promoter (Darnell et al., 1994; Ihle and Kerr, 1995). Other cytokines, including tumor necrosis factor- $\alpha$ (TNF- $\alpha$ ), have generally been found to further elevate this induction in rat astrocytes and microglia, while simultaneous stimulation with IFN $\alpha / \beta$ or transforming growth factor- $\beta$ (TGF- $\beta$ ) reduces IFN- $\gamma$ mediated Ia induction (Barna et al., 1989; Benveniste et al., 1989; Devajyothi et al., 1993; Schluesener, 1990). Concomitant with MHC induction, these cytokines can regulate the synthesis and release of bioactive compounds including reactive oxygen and nitrogen derivatives (Belosevic et al., 1988; Drapier et al., 1988; Nathan et al., 1983). Numerous reports have established nitric oxide as a critical mediator of inflammation and host defense. In the CNS, NO also participates in neurotransmission and is associated with specific forms of memory acquisition (Boje and Arora, 1992; Bredt et al., 1990; Liew et al., 1991; Moncada et al., 1991; Muller, 1996; Nathan and Hibbs, 1991; Stuehr and Nathan, 1989). A number of recent reports indicate primary cultures of astrocytes and microglia transcriptionally activate the calcium independent form of NO synthase (iNOS) and display elevated NO release following exposure to microbial products or cytokines (Boje and Arora, 1992; Chao et al., 1992; Galea et al., 1992; Simmons and Murphy, 1992).

While it is clear numerous phosphorylation events can occur during the induction of both MHC class II and NO, it is important to note that activation of intracellular signals pathways following cytokine exposure can show distinctive patterns among cell phenotypes, differentiation state, treatment protocol, and disease (Ina et al., 1987; Koide et al., 1988). Few studies have directly compared the regulation of MHC class II and NO in microglia and astrocytes most likely because of the limiting number of microglia available from primary cell preparations. The application of in situ histochemistry on individual coverslips has facilitated our study of microglia: by using relatively few cells to generate measurable signals for both class II mRNA and NO release, we have been able to simultaneously study the regulation of both molecules in a statistically significant fashion. Our objective in the current work was to directly compare astrocytes and microglia in their expression of MHC class II and NO following cytokine exposure. In addition, to evaluate the role of phosphorylation in these induction pathways, we have used various effectors of protein kinases and measured changes in cytokine driven microglial expression of $\mathrm{NO}$ and MHC class II. The results confirm that both astrocytes and microglia express Ia in response to IFN- $\gamma$ though induction in microglia is significantly higher. IFN- $\gamma+$ TNF- $\alpha$ further elevated Ia expression in both cells. However, IFN- $\gamma$ exposure produced quantitatively distinct patterns of NO release in the two cell types: Microglia consistently released substantial levels of NO while release by astrocytes was nominal. Genistein, a protein tyrosine kinase inhibitor, was most effective at inhibiting class II and NO induction in both astrocytes and microglia. Calphostin, a protein kinase $\mathrm{C}$ inhibitor, inhibited cytokine driven induction in microglia and, to a lesser degree, in astrocytes. Forskolin was most effective in inhibiting cytokine-induced class II expression in astrocytes, but produced little effect on nitric oxide release. These findings indicate astrocytes and microglia are capable of serving as immune effector cells in the CNS and that the cellular pathways underlying cytokine induction of both class II and NO implement overlapping as well as distinct signal transduction strategies.

\section{Materials and methods}

\subsection{Preparation of astrocytes and microglia}

Rat pups from timed pregnant Sprague Dawley rats (Zivic-Miller) were taken at postnatal day 2 for the preparation of primary cultures of astrocytes and microglia as described previously (Sasaki et al., 1989). Cells were grown in basal media (Dulbecco's modified Eagle Medium containing $4.5 \mathrm{~g} / 1$ glucose, $2 \mathrm{mM}$ L-glutamine, $50 \mathrm{IU} / \mathrm{ml}$ penicillin, $50 \mu \mathrm{g} / \mathrm{ml}$ streptomycin) supplemented with $10 \%$ fetal calf serum (Gibco). Microglia were plated on uncoated $18 \mathrm{~mm}$ glass coverslips (Fisher) in 12-well tissue culture plates $\left(2 \times 10^{5}\right.$ cells/well; Costar $)$ for in situ hybridization and immunohistochemistry. Macrophage/monocytes were identified by the surface antigen $\mathrm{CD} 11 \mathrm{~b} / \mathrm{c}$ by indirect immunofluorescence with mouse monoclonal antibody OX-42 (1:200; PharMingen). In addition, the acetylated low-density lipoprotein, labeled with the fluorescent probe $1,1^{\prime}$-dioctadecyl-3,3, $3^{\prime} 3^{\prime}$-tetramethyl-indocarbocyanate (DiI-ac-LDL; Biomedical Technologies, Stoughton, MA) was used to label phagocytic brain microglia/macrophage (Giulian and Baker, 1986). Both approaches indicated this enriched population was $>95 \%$ microglia/macrophage. Cells were used within 3 days of plating. Astrocytes were similarly plated following purification to produce enriched cultures of greater than 95\% purity as indicated by staining for glial fibrillary acidic protein (GFAP; 1:4000, rabbit anti-bovine IgG, Dakopatts). Since slight microglial contamination can significantly alter cytokine induced effects in enriched astrocytes cultures (Giulian, 1987; Simmons and Murphy, 1992), and microglia show poor survival following trypsinization, astrocytes were passaged at least twice prior to use.

\subsection{Culture additives}

Rat recombinant IFN- $\gamma$ (final conc. $100 \mathrm{U} / \mathrm{ml}$ ), and human recombinant TNF- $\alpha$ (50 ng/ml; Genentech) were added to wells in $1 / 10$ of final volume at $10 \times$ concentration in treatment media (see below). The tyrosine kinase inhibitor genistein (final conc. $25 \mu \mathrm{g} / \mathrm{ml}(93 \mu \mathrm{M})$ ) was 
purchased from GIBCO/BRL (Gaithersburg, MD). The broad spectrum serine-threonine protein kinase inhibitors staurosporine (1 $\mathrm{nM}$; Sigma) and the more specific PKC inhibitor calphostin C (5 nM; Sigma) were used. Activation of calphostin requires continuous light exposure: Treatments with this drug were conducted $15 \mathrm{~cm}$ from a 7 Watt fluorescent light above the cells in the tissue culture incubator. In the absence of calphostin, light exposure did not alter cytokine induced effects (data not shown). Forskolin (50 $\mu \mathrm{M}$; Sigma) stimulates adenylate cyclase to elevate intracellular levels of cAMP. Unless otherwise indicated, all compounds were dissolved in $100 \%$ dimethyl sulfoxide (DMSO).

\subsection{Treatment conditions}

Following adherence to 12-well plates, cells were incubated in $500 \mu \mathrm{l}$ treatment media (phenol red-free basal media supplemented with $2 \% \mathrm{FCS}$ and insulin $(10 \mathrm{mg} / 1)$, selenium $(6.7 \mu \mathrm{g} / \mathrm{l})$, and transferrin $(5.5 \mathrm{mg} / \mathrm{l})$ (ITS supplement, Gibco)) for $24 \mathrm{~h}$ prior to treatment. Drugs were applied in fresh treatment media to duplicate or triplicate wells $1.5 \mathrm{~h}$ prior to cytokine treatment. Cultures were then treated for 24 or $48 \mathrm{~h}$ with cytokine(s). Fifty microliter aliquots of the conditioned media were removed for assay of nitrite levels at the appropriate intervals. Cells were collected at $30 \mathrm{~h}$ for analysis of MHC class II mRNA and nitrite levels since this represented a time point near the plateau of class II expression and of reliably detectable nitrite levels in conditioned media of both cell types (see Figs. 1 and 2). Following treatment, cells on coverslips were washed $2 \times$ with Hank's buffered salt solution (HBSS), fixed in $4 \%$ paraformaldehyde $/ 70 \mathrm{mM}$ phosphate buffer, washed, and stored in $70 \%$ ethanol at $-20^{\circ} \mathrm{C}$.

\subsection{In situ hybridization histochemistry}

\subsubsection{RNA probes}

Hybridizing (antisense) or reference (sense) RNA probes were transcribed from a $1080 \mathrm{bp}$ fragment of the mouse MHC class II H2-IE- $\alpha$ cDNA ((Mathis et al., 1983); kindly provided by Dr. Etty Benveniste) using T3 or T7 RNA polymerase, components of the system II buffers (Promega), and $187.5 \mathrm{pmol}$ of $\left[\alpha^{3}{ }^{32} \mathrm{P}\right]-\mathrm{CTP}(800 \mathrm{Ci} / \mathrm{mmol}$; New England Nuclear). Probes are typically labeled to a specific activity $=1 \times 10^{9} \mathrm{cpm} / \mu \mathrm{g}$ and used within one day of synthesis.

\subsection{In situ hybridization}

The protocol for in situ hybridization has been published (Hellendall et al., 1992). Cells remained adhered to glass coverslips during hybridization, washing, and quantitation of signal. Coverslips were thawed at room temperature, dehydrated to $100 \%$ ethanol for permeabilization, rehydrated, and exposed to the riboprobe at $50^{\circ} \mathrm{C}$ overnight.
Following hybridization, cells were washed, digested with RNase, dehydrated, and coverslips were mounted on glass slides. Cells were subsequently apposed to a phosphor screen for quantitation using a Phosphorimager (Molecular Dynamics). Processing for in situ hybridization did not effect the cell adherence; thus imaging of the autoradiogram measured a composite signal generated by the vast majority of the original cell population. Pixel density values were obtained through ImageQuant software (Molecular Dynamics). The phosphorimage based quantitation was conducted so that the area imaged from each coverslip was consistent within each experiment and was intended to measure class II mRNA expression averaged

\section{a) Microglia}
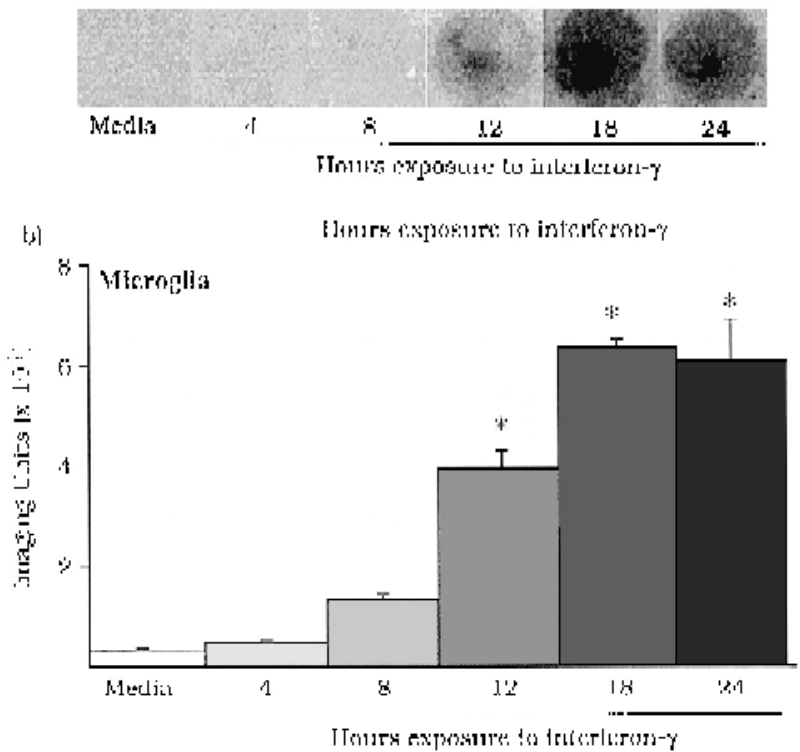

s)
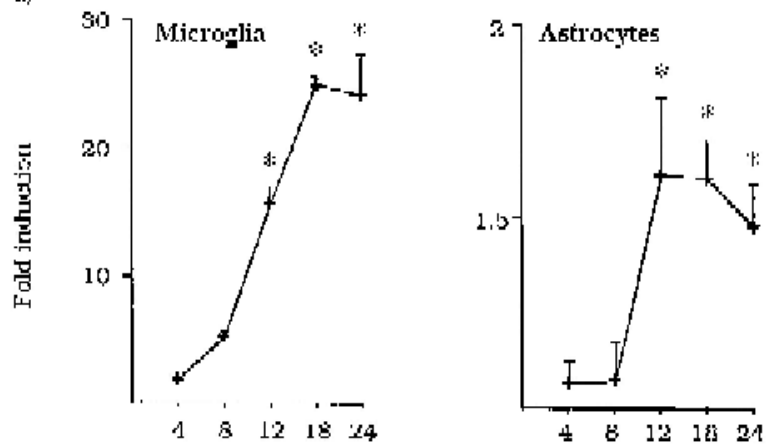

ILurs exposure to If $\mathrm{N}-\mathrm{Y}$

Fig. 1. Induction of MHC class II mRNA by interferon- $\gamma$ in astrocytes and microglia. Cells were grown on glass coverslips and treated with 100 $\mathrm{U} / \mathrm{ml}$ rat recombinant IFN- $\gamma$ for the indicated periods and hybridized with an $\left[\alpha_{-}{ }^{32} \mathrm{P}\right]$-mouse MHC class II H2-IE- $\alpha$ RNA probe. (a) Autoradiogram and (b) quantitation of microglial MHC class II mRNA signal following hybridization of eight coverslips per condition. (c) Comparison of class II MHC mRNA in microglia and astrocytes upon exposure to 100 $\mathrm{U} / \mathrm{ml}$ IFN- $\gamma$ for various periods. Representative of 4 experiments ( ${ }^{*}$ significantly different from control, $p<0.05$ ). 
a)

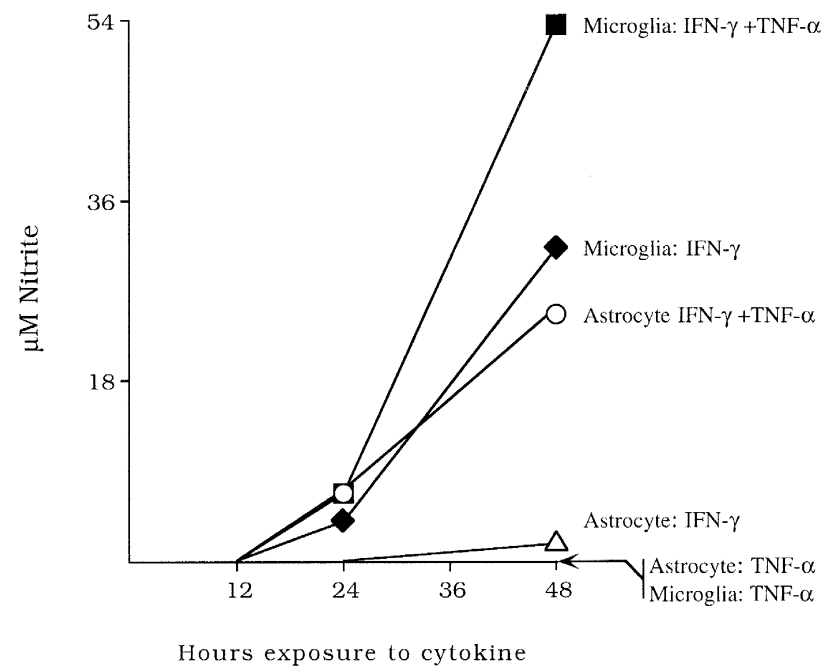

b)

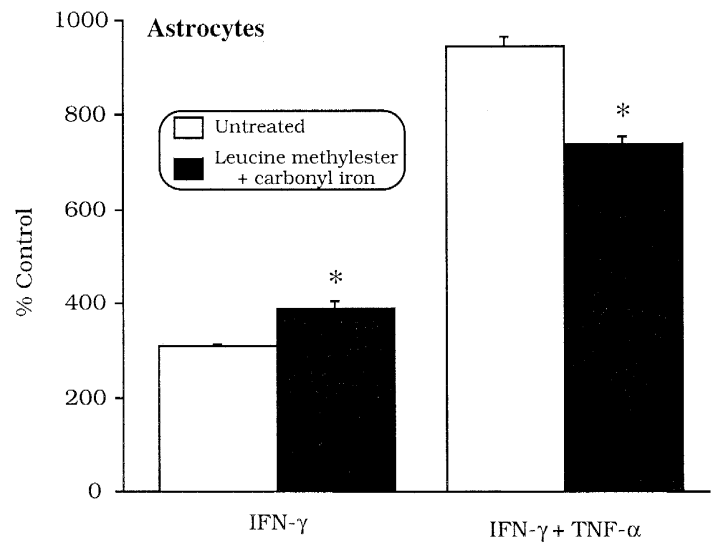

Fig. 2. Nitric oxide induction in glia. (a) Time course of nitrite release from astrocytes and microglia following treatment with interferon- $\gamma$ and/or TNF- $\alpha$. Enriched cultures were grown on glass coverslips in 12-well plates. Following 3 days in culture cells were treated with cytokines in $500 \mu 1$ treatment media. Aliquots $(50 \mu 1)$ of media were removed at indicated times and assayed for nitrite concentration. Nitrite was not detected in untreated or TNF- $\alpha$ treated cultures. All standard errors were within $10 \%$ of the mean. Significantly higher levels of nitrate were found in the conditioned media of IFN- $\gamma$ or IFN- $\gamma+$ TNF- $\alpha$ exposed microglia than in similarly treated astrocytes. (b) Effect of leucine methylester plus carbonyl iron (LME/CI) treatment on cytokine induced nitric oxide release by rat astrocytes. Cells were treated with IFN- $\gamma$ for $48 \mathrm{~h}$ with or without LME/CI and the conditioned media was assayed for nitrite concentration. Data are from one experiment containing six replicates per condition ( ${ }^{*}$ significantly different from untreated group, $p<0.05)$.

over the entire population of cells on each coverslip. These values ranged from 500 optical density imaging units for untreated cells to 150,000 units for microglia treated with IFN- $\gamma+$ TNF- $\alpha$ for $30 \mathrm{~h}$. Images of the autoradiograms (Kodak XAR-5 film) exposed to the coverslips were made using a light box and a video camera (Model CCD-72, Dage MTI) and were processed through image capture (Image 1.47) and graphics (Canvas 3.5.4; Deneba) software on Macintosh Quadra 650 and Power Macintosh
$7100 / 80$ systems. The signal generated by hybridization of the sense strand was at the level of untreated cells (data not shown); as this signal intensity was trivial with respect to the induced levels, this background was not subtracted.

\subsection{Nitrite assay}

An estimation of nitric oxide production was made by measuring nitrite $\left(\mathrm{NO}_{2}^{-}\right)$concentration in the conditioned media (CM) over cells (Chao et al., 1992; Corradin et al., 1993; Ding et al., 1988). One hundred microliters of Greiss reagent (1\% sulfanilamide in $30 \%$ acetic acid and $0.1 \%$ $\mathrm{N}$-(1-napthyl)ethylene-diamine diHCl in $60 \%$ acetic acid) was added to $50 \mu \mathrm{l}$ of $\mathrm{CM}$ in a 96 well microtiter plate. Following a $5 \mathrm{~min}$ incubation at room temperature, absorbances were read at $540 \mathrm{~nm}$ on a Multiskan MCC/340 plate reader. Sample nitrite concentration was calculated from the regression equation generated from sodium nitrite (Sigma) standards run in each assay.

\subsection{Statistics}

Statistical analysis of the data was performed using Student's $t$-test and Chi square test (at 95\% confidence limits) for unpaired observations followed by ANOVA and post hoc analysis by Fisher's PLSD test (at 95\%). Statistics generated in Statview 4.1 (Abacus).

\section{Results}

3.1. Cytokine regulation of MHC class II expression release and nitric oxide by microglia and astrocytes

\subsubsection{MHC class II}

Initial studies were conducted to establish the time course of class II MHC mRNA detection by in situ hybridization in primary cultures of astrocytes and microglia on coverslips following IFN- $\gamma$ exposure. Cells were treated for various periods to measure Ia transcript levels and processed for in situ hybridization using the mouse MHC class II $\mathrm{E} \alpha$ cDNA probe as detailed in Section 2. Since primary cultures of microglia exhibit minimal basal proliferation, their limiting cell number has made in vitro analysis of their properties difficult. Our ability to generate semi-quantitative mRNA data from individual $18 \mathrm{~mm}$ coverslips has allowed us to analyze a large number of conditions and replicates.

Induction of Ia transcript in microglia was initially observed at $8 \mathrm{~h}$ following IFN- $\gamma$ addition and showed a plateau of maximal induction at $18-24 \mathrm{~h}$ (Fig. 1a and b). The relatively low number of cells $\left(\sim 2 \times 10^{5}\right)$ required to detect the signal on coverslips suggests this approach may circumvent the limiting number of microglia available from the newborn rat brain. Astrocytes expressed class II transcript in a temporal pattern similar to, though on a 
level significantly less than that of microglia (Fig. 1c). In 4 experiments, MHC class II mRNA levels increased by $6-30 \times$ in microglia upon IFN- $\gamma$ treatment and $1.5-4 \times$ in astrocytes. When TNF- $\alpha$ was included with IFN- $\gamma$, there was a modest additional induction of class II transcript in microglia $(1.2-2 \times)$ and astrocytes $(1.5-3 \times)$.
Hybridization using a sense strand control probe gave background levels of signal (data not shown).

\subsection{Nitric oxide}

Conditioned media (CM) from cells treated with IFN- $\gamma$, TNF- $\alpha$, or IFN- $\gamma+$ TNF- $\alpha$ for up to $48 \mathrm{~h}$ was used to

\section{MHC class II mRNA}
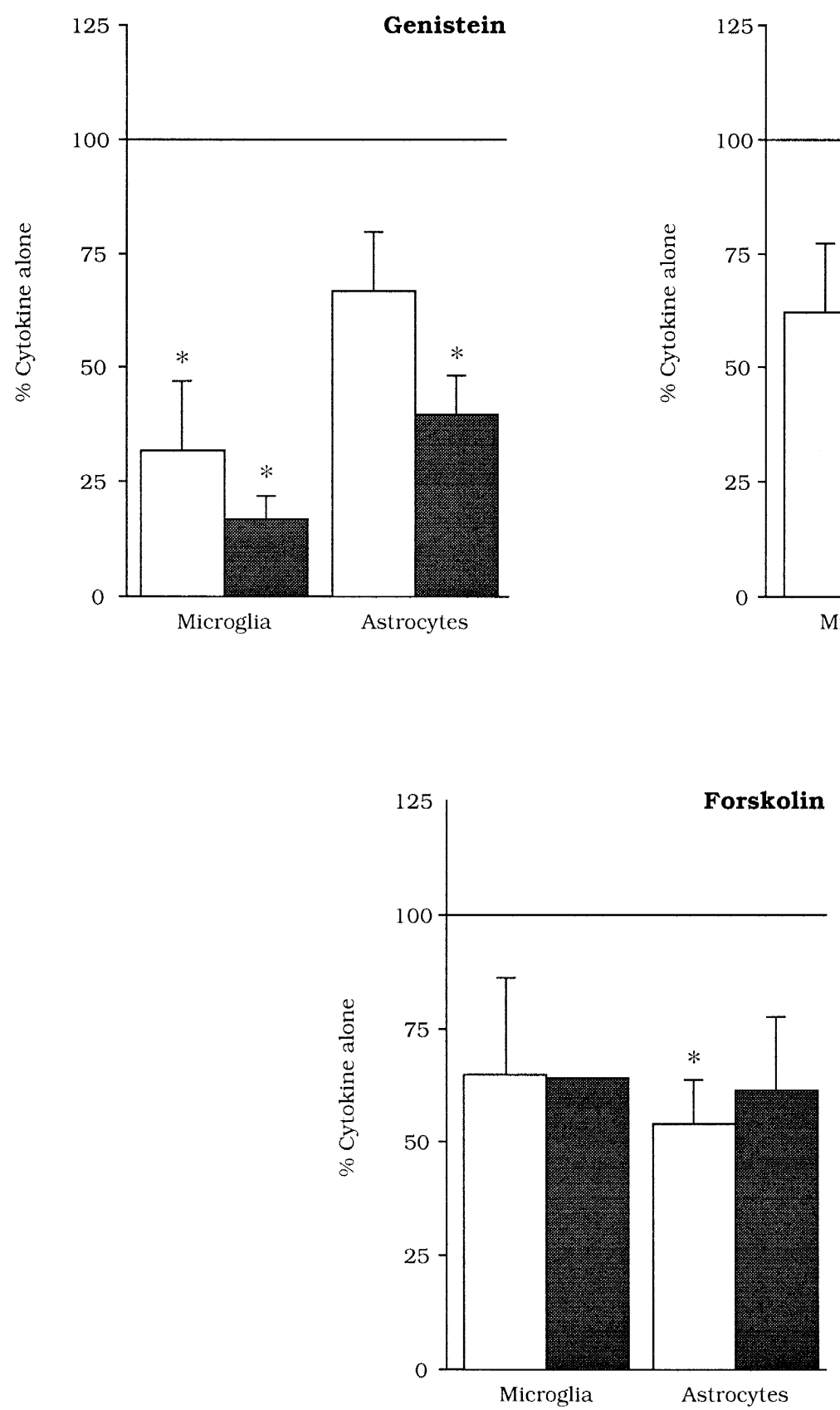

Fig. 3. Expression MHC class II mRNA in astrocytes and microglia following exposure to cytokines and various inhibitors of intracellular signaling systems. Cells were exposed to inhibitors $1.5 \mathrm{~h}$ prior to cytokine application. Data are expressed as percent of treatment with cytokine alone. Each value represents the mean $\pm \mathrm{SE}$ of at least 3 independent experiments performed in triplicate $\left({ }^{*}\right.$ significantly different from control, $p<0.05$; data lacking error bars represent $1-2$ experiments). 
assay for nitrite accumulation, a measure of NOS activity and nitric oxide release (Fig. 2). Astrocytes and microglia released very low levels $(<0.5 \mu \mathrm{M})$ of nitrite prior to exposure to cytokines. In response to $24 \mathrm{~h} \mathrm{IFN}-\gamma$ treatment, microglia produced significant NO release, ranging from $5 \mu \mathrm{M}$ to $15 \mu \mathrm{M}$ per well but higher levels were also observed (Fig. 2a). This induction was significantly elevated upon longer treatment with IFN- $\gamma$. In comparison, astrocytes released nominal levels of NO following 24 or $48 \mathrm{~h}$ treatment with IFN- $\gamma$ (Fig. 2a) and the measured

\section{Nitric Oxide}
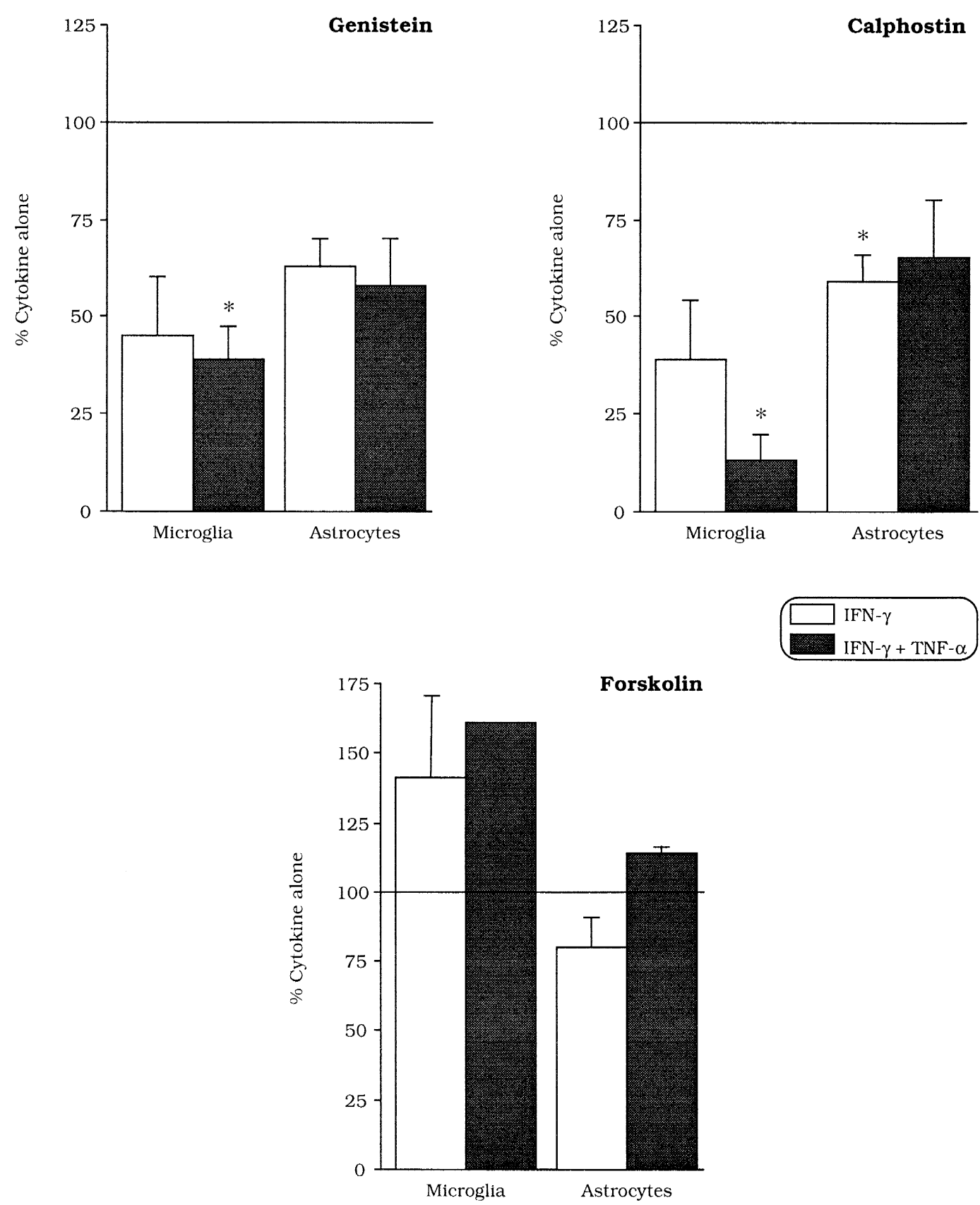

Fig. 4. Release of nitric oxide from astrocytes and microglia following exposure to cytokines and various inhibitors of intracellular signaling systems. Cells were exposed to inhibitors $1.5 \mathrm{~h}$ prior to cytokine application. Data are expressed as percent of treatment with cytokine alone. Each value represents the mean $\pm \mathrm{SE}$ of at least 3 independent experiments performed in triplicate ( ${ }^{*}$ significantly different from control, $p<0.05$; data lacking error bars represent 1-2 experiments). 
nitrite in the conditioned media was often at the detection limit of the assay. The difference between microglial and astrocyte NO release was most notable at $48 \mathrm{~h}$ of IFN- $\gamma$ treatment, where the induction level differed by $10-20$ fold.

Whereas TNF- $\alpha$, when applied alone, did not stimulate NO release in either cell type, the combination of IFN- $\gamma$ and TNF- $\alpha(\mathrm{I}+\mathrm{T})$ was an agonist for NO generation in both glial populations. Nitrite was measured at similar levels in astrocytes and microglia following $24 \mathrm{~h}$ of combined cytokine treatment, while longer exposure again resulted in higher microglial release (Fig. 2a). Although astrocyte and microglia appear to be distinct in the degree of release of nitric oxide in response to IFN- $\gamma$ alone, this difference is diminished during the synergistic response to $\mathrm{I}+\mathrm{T}$.

Treatment of astrocytes for $48 \mathrm{~h}$ with cytokines and the lysosomotrophic agent leucine-methyl-ester plus carbonyl iron (LME/CI), which greatly reduces contaminating microglia from enriched astrocyte cultures (Giulian and Baker, 1986) reduced IFN- $\gamma+$ TNF- $\alpha$ driven NO release by $21 \%$ (Fig. 2b). This indicates contaminating microglia are a minor source of NO synthesis in our enriched astrocyte cultures.

\subsection{Regulation of cytokine driven MHC class II and nitric oxide release by protein kinase effectors}

The role of protein kinase-mediated intracellular signaling systems in cytokine induced MHC class II expression and NO release was studied through the application of selected inhibitors. An initial protocol was designed to apply inhibitors at various time points prior to, simultaneous with, and subsequent to the addition of cytokines. However, inhibitors are not equally cell permeable and, in general, should be given at least 90 min prior to cytokine exposure. Cells exposed to drugs were thus uniformly treated for $1.5 \mathrm{~h}$ prior to cytokine exposure.

\subsection{Drugs alone}

Exposure to inhibitors of tyrosine kinase (genistein), protein kinase $\mathrm{C}$ (calphostin, staurosporine), or an inducer of cAMP (forskolin), alone had little effect class II MHC transcript levels or NO release in either astrocytes or microglia (data not shown). One deviation from this pattern in NO measurements was staurosporine: This PKC inhibitor given alone consistently induced NO release from treated cells, and further enhanced cytokine stimulated release. Thus, staurosporine could not be used for these studies. This finding is consistent with a recent report showing staurosporine dose dependently $(10-100 \mathrm{nM})$ increased the expression of constitutive NOS (cNOS) mRNA and protein and elevated nitrite release in bovine endothelial cells (Ohara et al., 1995). The solvent DMSO did not inhibit any cytokine effects.

\subsection{Altered signal transduction and class II MHC expres- sion}

To determine the intracellular pathways responsible for class II MHC and NO induction, astrocytes and microglia were treated with inhibitors prior to exposure to IFN- $\gamma$ and/or TNF- $\alpha$. A composite of data generated from a series of experiments are shown in Fig. 3. The broad spectrum tyrosine kinase inhibitor genistein was the most consistent inhibitory agent used: IFN- $\gamma$ or I $+\mathrm{T}$ induced MHC class II mRNA was inhibited by this drug, although the reduction is most substantial for microglia. Inhibition of tyrosine kinase by genistein led to a significant diminution of $\mathrm{I}+\mathrm{T}$ driven class II transcript induction in microglia (87\% reduction) and astrocytes $(61 \%)$. This represents a higher degree of inhibition when compared to cells exposed to IFN- $\gamma$ alone. Inhibition of PKC also blocked class II induction. Calphostin, a highly specific PKC inhibitor, significantly inhibited class II induction by $\mathrm{I}+\mathrm{T}$ in microglia while consistently reducing induction by IFN- $\gamma$ (Fig. 3). Calphostin had a limited effect on class II expression by astrocytes. The adenylate cyclase activator, forskolin, significantly inhibited IFN- $\gamma$ driven class II MHC induction in astrocyte cultures and produced a pattern of diminished induction in the other treatment conditions.

\subsection{Altered signal transduction and NO release}

Studies evaluating drug effects on NO release in microglia and astrocytes following IFN- $\gamma$ treatment or combined $\mathrm{I}+\mathrm{T}$ treatment are shown in Fig. 4. Genistein produced a distinct trend towards inhibited NO release in a similar manner for IFN- $\gamma$ or I $+\mathrm{T}$ treatment. Microglial release was inhibited by $50-60 \%$ while astrocytes showed a $40-50 \%$ reduction. The PKC inhibitor calphostin significantly reduced $\mathrm{NO}$ induction in $\mathrm{I}+\mathrm{T}$ treated microglial cultures $(>85 \%)$. Although its effects were not as dramatic, this drug also significantly inhibited NO release from IFN- $\gamma$ induced astrocytes. Forskolin treatment suggested slight inhibitory activity for astrocytes with IFN- $\gamma$ treatment while it was without effect in microglia. In fact, forskolin augmented both IFN- $\gamma$ and $\mathrm{I}+\mathrm{T}$ driven $\mathrm{NO}$ release in microglial cells.

\section{Discussion}

Our objective in the current studies was to (a) directly compare microglia and astrocytes for their capacity to express MHC class II and nitric oxide, two molecules of fundamental importance for immune mediation in the CNS, following cytokine stimulation; and (b) to similarly compare the effects of reagents which modulate intracellular signaling pathways underlying cytokine induction. The findings are: (1) The two cell types were clearly distinct in 
their response to cytokines: astrocyte expression was consistently and significantly lower on both measures suggesting that microglia are a more robust effector population. The most notable difference was in NO release: IFN- $\gamma$ elicited NO release in astrocytes at nominal levels while it induced high levels of NO release in microglia. (2) $\mathrm{Cy}-$ tokine induced upregulation of MHC class II in microglia was diminished by modulators of a protein tyrosine kinase, protein kinase $\mathrm{C}$ as well as cAMP, suggesting the involvement of multiple signal transducing events in class II activation. (3) The pattern of NO release in both cell types showed some similarities to the inhibitory effects for class II induction but this correlation was low. Inhibition of tyrosine kinase and PKC also affected NO release, but, in contrast to Ia induction, forskolin had little effect on NO release. The changes Ia mRNA levels and NO production under the various treatment conditions may also reflect distinct levels of regulation: While regulation of steadystate Ia transcript levels is likely to occur at the transcriptional level (Ting and Baldwin, 1993), overall NO production may involve a number of sequential events including modulation of NOS catalytic activity. These findings indicate that in the presence of IFN- $\gamma$ or IFN- $\gamma+$ TNF- $\alpha$, astrocytes and microglia are capable of behaving as immune effector cells in the CNS although microglia produce an augmented response. In addition, the cellular pathways underlying cytokine induction of both class II and NO implement overlapping as well as distinct signal transduction strategies.

\subsection{Class II MHC induction by cytokines}

Microglia expressed high levels of MHC class II mRNA in response to IFN- $\gamma$ which was further elevated by TNF- $\alpha$. The degree of induction was 10-15-fold higher in microglia than astrocytes. TNF- $\alpha$ alone was without effect in either astrocytes or microglia. However, both phenotypes displayed a consistent further elevation of IFN- $\gamma$ class II induction in the presence of TNF- $\alpha$. In addition, microglia were found to have low but detectable constitutive levels of $\mathrm{MHC}$ transcripts, consistent with earlier reports measuring constitutive protein expression and one of a number of traits these cells have in common with peripheral, terminally differentiated monocytic cells (Gehrmann et al., 1993; Panek and Benveniste, 1995; Williams et al., 1992). Astrocytes showed very little basal MHC class II mRNA expression. Microglia are clearly more responsive to stimuli in the brain parenchyma and appear to maintain immune surveillance by their highly branched morphology and the ability to express such factors as was found in this study. The view that microglia are the primary effector during immune activation of the brain is consistent with the observation that $\mathrm{Ia}^{+}$microglial cells are detected at a much higher frequency than $\mathrm{Ia}^{+}$astrocytes in vivo following various perturbations.

\subsection{Pathways of cytokine regulation of class II MHC}

Our studies have shown strong patterns of inhibition of class II expression when astrocytes or microglia are treated with selected inhibitors of protein tyrosine kinases, protein kinase $\mathrm{C}$, or with forskolin, an activator of adenylate cyclase, prior to cytokine exposure. The role of proteintyrosine phosphorylation in the intercellular activation pathway IFN- $\gamma$ has been described in detail in recent years (for a review see Ihle and Kerr, 1995). Inhibition of tyrosine phosphorylation blocks IFN- $\gamma$ signal transduction (Shuai et al., 1992; Steimle et al., 1994) and this is concordant with our findings that genistein inhibits class II MHC induction in brain glia.

Our studies also indicate protein kinase $\mathrm{C}$ activity is important for induction of class II transcripts in microglia. Serine phosphorylation is necessary for transcriptional activation via the Stat $1 \alpha$ dimer/GAS complex, required components of the IFN- $\gamma$ induced class II expression (Wen et al., 1995). IFN- $\gamma$ can stimulate PKC in murine macrophages (Hamilton et al., 1985) and the resultant class II expression can be blocked by $\mathrm{H} 7$ or staurosporine (Politis et al., 1993; Politis and Vogel, 1990), the latter by inhibiting phosphorylation of Stat $1 \alpha$ (Shuai et al., 1992). In addition, direct injection of PKC into human peritoneal macrophages strongly activates class II expression while components of the protein kinase A pathway do not (Smith et al., 1992). In rat astrocytes, IFN- $\gamma$ increased total PKC activity although exposure to PMA did not effect Ia levels (Benveniste et al., 1991). This PKC activity and Ia induction was blocked by $\mathrm{H} 7$ or staurosporine. It appears that for many phenotypes, PKC induction is necessary but not sufficient to induce Ia expression.

We have found that forskolin, a cell permeable inducer of adenylate cyclase, restricted cytokine induced expression of class II in microglia and astrocytes. While prior studies from this lab have found that a lower concentration of forskolin $(10 \mu \mathrm{M})$ did not alter class II MHC expression by microglia (Sasaki et al., 1990), the current studies suggest a pattern of inhibition of IFN- $\gamma$ elicited expression with a higher dose of forskolin (Fig. 3). Activation of adenylate cyclase appears to inhibit class II expression. During the preparation of this manuscript, a paper has shown that forskolin inhibits STAT induction thus providing a molecular basis for this inhibition (David and Petricoin, 1996).

\subsection{NO induction by cytokines}

We have found microglia can release significant amounts of NO when exposed to IFN- $\gamma$; TNF- $\alpha$ works in synergy to further elevate this release. This pattern was found to be distinct from astrocytes where an extremely low level of NO was released in response to IFN- $\gamma$ alone. Although IFN- $\gamma$ and TNF- $\alpha$ did induce release in astrocytes these levels remained lower than microglia. Our data 
indicate astrocytes and microglia differentially regulate NO synthesis and suggests astrocytes may either be under much stricter control or may require priming signals to initiate induction.

TNF- $\alpha$ may also be a downstream mediator of IFN- $\gamma$ induction: application of anti-TNF- $\alpha$ antibodies can block IFN- $\gamma$ induction in murine macrophages (Jun et al., 1993) while in rodent macrophages, the combination of IFN- $\gamma+$ TNF- $\alpha$ produces a significant elevation of NO over that found for IFN- $\gamma$ alone (Ding et al., 1988). Our data, consistent with these studies, indicate TNF- $\alpha$ is an important mediator of NO induction in the context of priming or simultaneous exposure to other releasing agents. Other reports have noted that a substantial reduction of a slight (5-10\%) microglia contamination from astrocyte cultures results in a significant diminution (Simmons and Murphy, 1992) or complete elimination (Galea et al., 1992) of LPS driven NO release. Staining for microglia with the phenotype marker $\mathrm{CD} 11 \mathrm{~b} / \mathrm{c}$ in our enriched astrocytes cultures indicated little microglial contamination $(\sim 0.1-0.5 \%)$. Removal of microglia using LME/CI produced a modest $20 \%$ reduction in NO output by $\mathrm{I}+\mathrm{T}$ treated astrocytes indicating that astrocytes are clearly responsible for the bulk of NO output by these enriched cultures.

\subsection{Pathways of cytokine regulation of $N O$}

Inhibition of tyrosine phosphorylation and an inhibitor of PKC produced a $50 \%$ to $85 \%$ reduction of cytokine induced NO release from microglia. The involvement of tyrosine kinase agrees with studies of macrophage/monocytes and other cells upon induction by a number of cytokines and bacterial products (Akarasereenont et al., 1994; Dong et al., 1993a; Dong et al., 1993b; Paul et al., 1995; Terenzi et al., 1995; Weinstein et al., 1991). Genistein has been shown to inhibit LPS or LPS + IFN- $\gamma$ stimulated iNOS activity in rat astrocytes and a glioma cell line (Feinstein et al., 1994; Simmons and Murphy, 1994). In parallel with our findings, inhibition of PKC activity with Ro-318220 can block IFN- $\gamma$ induced release of NO from murine macrophage (Paul et al., 1995; Severn et al., 1992) while staurosporine can increase constitutive expression of ecNOS in vascular smooth muscle cells (Ohara et al., 1995). In contrast to inhibitions of tyrosine kinase and PKC, forskolin did not have a significant inhibiting effect on NO release and, in most treatment groups, it slightly enhanced NO release. This is clearly distinct from the inhibitory effect of this drug on Ia induction by cytokines in these glial cells.

In summary, the cytokine induced expression of class II MHC and NO by microglia is a reflection of the importance of this cell in providing a rapid and concerted response to an altered CNS environment. Our data show effectors of intracellular pathways modulate the levels of these molecules in a manner suggesting both shared (or parallel) and distinct utilization of components of these signaling mechanisms. These data also indicate parallel and distinct response patterns between microglia and astrocytes. The ability to selectively activate or inhibit will further the opportunity to explore the role of class II MHC of NO expression in microglia during the progression of pathology in the central nervous system.

\section{Acknowledgements}

Human recombinant TNF- $\alpha$ was a generous gift of Genentech, So. San Francisco, CA. The secretarial and managerial skills of Allison Kron were critical for the successful completion of this work. This work is supported (in part) by Postdoctoral Fellowship FA 1109-A-1 to R.P.H. and grant RG-1785-C-3 to J.P.-Y.T. from the National Multiple Sclerosis Society.

\section{References}

Akarasereenont, P., Mitchell, J.A., Appleton, I., Thiemermann, C. and Vane, J.R. (1994) Involvement of tyrosine kinase in the induction of cyclo-oxygenase and nitric oxide synthase by endotoxin in cultured cells. Br. J. Pharmacol. 113, 1522-1528.

Barna, B.P., Chou, S.M., Jacobs, B., Yen-Lieberman, B. and Ransohoff, R.M. (1989) Interferon-beta impairs induction of HLA-DR antigen expression in cultured adult human astrocytes. J. Neuroimmunol. 23, 45-53.

Belosevic, M., Davis, C.E., Meltzer, M.S. and Nacy, C.A. (1988) Regulation of activated macrophage antimicrobial activities. Identification of lymphokines that cooperate with IFN-gamma for induction of resistance to infection. J. Immunol. 141, 890-896.

Benveniste, E.N., Sparacio, S.M. and Bethea, J.R. (1989) Tumor necrosis factor-alpha enhances interferon-gamma-mediated class II antigen expression on astrocytes. J. Neuroimmunol. 25, 209-219.

Benveniste, E.N., Vidovic, M., Panek, R.B., Norris, J.G., Reddy, A.T. and Benos, D.J. (1991) Interferon-gamma-induced astrocyte class II major histocompatibility complex gene expression is associated with both protein kinase $\mathrm{C}$ activation and $\mathrm{Na}^{+}$entry. J. Biol. Chem. 266, 18119-18126.

Boje, K.M. and Arora, P.K. (1992) Microglial-produced nitric oxide and reactive nitrogen oxides mediate neuronal cell death. Br. Res. 587, 250-256.

Bredt, D.S., Hwang, P.M. and Snyder, S.H. (1990) Localization of nitric oxide synthase indicating a neural role for nitric oxide. Nature 347, $768-770$.

Chao, C.C., Hu, S., Molitor, T.W., Shaskan, E.G. and Peterson, P.K. (1992) Activated microglia mediate neuronal cell injury via a nitric oxide mechanism. J. Immunol. 149, 2736-2741.

Corradin, S.B., Mauel, J., Donini, S.D., Quattrocchi, E. and RicciardiCastagnoli, P. (1993) Inducible nitric oxide synthase activity of cloned murine microglial cells. Glia 7, 255-262.

Cresswell, P. (1990) Immunology: questions of presentation. Nature 343, 593-594.

Darnell, Jr., J.E., Kerr, I.M. and Stark, G.R. (1994) Jak-STAT pathways and transcriptional activation in response to IFNs and other extracellular signaling proteins. Science 264, 1415-1421.

David, M. and Petricoin, C. (1996) Activation of protein kinase A inhibits interferon induction of the Jak/Stat pathway in U266 cells. J. Biol. Chem. 271, 4585-4588.

Devajyothi, C., Kalvakolanu, I., Babcock, G.T., Vasavada, H.A., Howe, P.H. and Ransohoff, R.M. (1993) Inhibition of interferon-gamma-induced major histocompatibility complex class II gene transcription by 
interferon-beta and type beta 1 transforming growth factor in human astrocytoma cells. Definition of cis-element. J. Biol. Chem. 268, 18794-18800.

Ding, A.H., Nathan, C.F. and Stuehr, D.J. (1988) Release of reactive nitrogen intermediates and reactive oxygen intermediates from mouse peritoneal macrophages. Comparison of activating cytokines and evidence for independent production. J. Immunol. 141, 2407-2412.

Dong, Z., O'Brian, C.A. and Fidler, I.J. (1993a) Activation of tumoricidal properties in macrophages by lipopolysaccharide requires proteintyrosine kinase activity. J. Leukocyte Biol. 53, 53-60.

Dong, Z., Qi, X., Xie, K. and Fidler, I.J. (1993b) Protein tyrosine kinase inhibitors decrease induction of nitric oxide synthase activity in lipopolysaccharide-responsive and lipopolysaccharide-nonresponsive murine macrophages. J. Immunol. 151, 2717-2724.

Drapier, J.C., Wietzerbin, J. and Hibbs, Jr., J.B. (1988) Interferon-gamma and tumor necrosis factor induce the L-arginine-dependent cytotoxic effector mechanism in murine macrophages. Eur. J. Immunol. 18, $1587-1592$

Feinstein, D.L., Galea, E., Cermak, J., Chugh, P., Lyandvert, L. and Reis, D.J. (1994) Nitric oxide synthase expression in glial cells: suppression by tyrosine kinase inhibitors. J. Neurochem. 62, 811-814.

Fierz, W., Endler, B., Reske, K., Wekerle, H. and Fontana, A. (1985) Astrocytes as antigen-presenting cells. I. Induction of Ia antigen expression on astrocytes by $\mathrm{T}$ cells via immune interferon and its effect on antigen presentation. J. Immunol. 134, 3785-3793.

Fontana, A., Fierz, W. and Wekerle, H. (1984) Astrocytes present myelin basic protein to encephalitogenic T-cell lines. Nature 307, 273-276.

Frei, K., Siepl, C., Groscurth, P., Bodmer, S., Schwerdel, C. and Fontana, A. (1987) Antigen presentation and tumor cytotoxicity by interferongamma-treated microglial cells. Eur. J. Immunol. 17, 1271-1278.

Galea, E., Feinstein, D.L. and Reis, D.J. (1992) Induction of calcium-independent nitric oxide synthase activity in primary rat glial cultures Proc. Natl. Acad. Sci. USA 89, 10945-10949.

Gehrmann, J., Banati, R.B. and Kreutzberg, G.W. (1993) Microglia in the immune surveillance of the brain: human microglia constitutively express HLA-DR molecules. J. Neuroimmunol. 48, 189-198.

Giulian, D. (1987) Ameboid microglia as effectors of inflammation in the central nervous system. J. Neurosci. Res. 18, 155-171, 132-153.

Giulian, D. and Baker, T.J. (1986) Characterization of ameboid microglia isolated from developing mammalian brain. J. Neurosci. 6, 21632178.

Hamilton, T.A., Becton, D.L., Somers, S.D., Gray, P.W. and Adams, D.O. (1985) Interferon-gamma modulates protein kinase C activity in murine peritoneal macrophages. J. Biol. Chem. 260, 1378-1381.

Hayes, G.M., Woodroofe, M.N. and Cuzner, M.L. (1987) Microglia are the major cell type expressing MHC class II in human white matter. J. Neurol. Sci. 80, 25-37.

Hellendall, R.P., Schambra, U., Liu, J., Breese, G.R., Millhorn, D.E. and Lauder, J.M. (1992) Detection of serotonin receptor transcripts in the developing nervous system. J. Chem. Neuroanat. 5, 299-310.

Ihle, J.N. and Kerr, I.M. (1995) Jaks and Stats in signaling by the cytokine receptor superfamily. Trends Genet. 11, 69-74.

Ina, Y., Koide, Y., Nezu, N. and Yoshida, T.O. (1987) Regulation of HLA class II antigen expression: intracellular signaling molecules responsible for the regulation by IFN-gamma and cross-linking of $\mathrm{Fc}$ receptors in HL-60 cells. J. Immunol. 139, 1711-1717.

Jun, C.D., Kim, S.H., Soh, C.T., Kang, S.S. and Chung, H.T. (1993) Nitric oxide mediates the toxoplasmastatic activity of murine microglial cells in vitro. Immunol. Invest. 22, 487-501.

Koide, Y., Ina, Y., Nezu, N. and Yoshida, T.O. (1988) Calcium influx and the $\mathrm{Ca}^{2+}$-calmodulin complex are involved in interferon-gammainduced expression of HLA class II molecules on HL-60 cells. Proc. Natl. Acad. Sci. USA 85, 3120-3124.

Liew, F.Y., Li, Y., Moss, D., Parkinson, C., Rogers, M.V. and Moncada, S. (1991) Resistance to Leishmania major infection correlates with the induction of nitric oxide synthase in murine macrophages. Eur. J. Immunol. 21, 3009-3014.

Mathis, D.J., Benoist, C.O., Williams, V.E.d., Kanter, M.R. and McDe- vitt, H.O. (1983) The murine E alpha immune response gene. Cell 32, $745-754$.

Moncada, S., Palmer, R.M. and Higgs, E.A. (1991) Nitric oxide: physiology, pathophysiology, and pharmacology. Pharmacol. Rev. 43, 109142

Muller, U. (1996) Inhibition of nitric oxide synthase impairs a distinct formn of long-term memory in the honeybee, Apis mellifera. Neuron $16,541-549$

Nathan, C.F. and Hibbs, Jr., J.B. (1991) Role of nitric oxide synthesis in macrophage antimicrobial activity. Curr. Opin. Immunol. 3, 65-70.

Nathan, C.F., Murray, H.W., Wiebe, M.E. and Rubin, B.Y. (1983) Identification of interferon-gamma as the lymphokine that activates human macrophage oxidative metabolism and antimicrobial activity. J. Exp. Med. 158, 670-689.

Ohara, Y., Sayegh, H.S., Yamin, J.J. and Harrison, D.G. (1995) Regulation of endothelial constitutive nitric oxide synthase by protein kinase C. Hypertension 25, 415-420.

Panek, R.B. and Benveniste, E.N. (1995) Class II MHC gene expression in microglia. Regulation by the cytokines IFN-gamma, TNF-alpha, and TGF-beta. J. Immunol. 154, 2846-2854.

Paul, A., Pendreigh, R.H. and Plevin, R. (1995) Protein kinase C and tyrosine kinase pathways regulate lipopolysaccharide-induced nitric oxide synthase activity in RAW 264.7 murine macrophages. Br. J. Pharmacol. 114, 482-488.

Politis, A.D., Sivo, J. and Vogel, S.N. (1993) Multiple pathways of interferon-induced gene expression in murine macrophages. J. Leukocyte Biol. 53, 583-590.

Politis, A.D. and Vogel, S.N. (1990) Pharmacologic evidence for the requirement of protein kinase $\mathrm{C}$ in IFN-induced macrophage $\mathrm{Fc}$ gamma receptor and Ia antigen expression. J. Immunol. 145, 37883795 .

Pulver, M., Carrel, S., Mach, J.P. and de Tribolet, N. (1987) Cultured human fetal astrocytes can be induced by interferon-gamma to express HLA-DR. J. Neuroimmunol. 14, 123-133.

Sasaki, A., Levison, S.W. and Ting, J.P. (1989) Comparison and quantitation of Ia antigen expression on cultured macroglia and ameboid microglia from Lewis rat cerebral cortex: analyses and implications. J. Neuroimmunol. 25, 63-74.

Sasaki, A., Levison, S.W. and Ting, J.P. (1990) Differential suppression of interferon-gamma-induced Ia antigen expression on cultured rat astroglia and microglia by second messengers. J. Neuroimmunol. 29, 213-222.

Schluesener, H.J. (1990) Transforming growth factors type beta 1 and beta 2 suppress rat astrocyte autoantigen presentation and antagonize hyperinduction of class II major histocompatibility complex antigen expression by interferon-gamma and tumor necrosis factor-alpha. J. Neuroimmunol. 27, 41-47.

Severn, A., Wakelam, M.J. and Liew, F.Y. (1992) The role of protein kinase $\mathrm{C}$ in the induction of nitric oxide synthesis by murine macrophages. Biochem. Biophys. Res. Commun. 188, 997-1002.

Shuai, K., Schindler, C., Prezioso, V.R. and Darnell, Jr., J.E. (1992) Activation of transcription by IFN-gamma: tyrosine phosphorylation of a 91-kD DNA binding protein. Science 258, 1808-1812.

Simmons, M.L. and Murphy, S. (1992) Induction of nitric oxide synthase in glial cells. J. Neurochem. 59, 897-905.

Simmons, M.L. and Murphy, S. (1994) Roles for protein kinases in the induction of nitric oxide synthase in astrocytes. Glia 11, 227-234.

Smith, M.R., Ramsburg, E.A., Kung, H.F. and Durum, S.K. (1992) Components of the protein kinase $\mathrm{C}$ pathway induce Ia expression after injection into macrophages. J. Immunol. 149, 1304-1310.

Steimle, V., Siegrist, C.A., Mottet, A., Lisowska-Grospierre, B. and Mach, B. (1994) Regulation of MHC class II expression by interferon-gamma mediated by the transactivator gene CIITA. Science $265,106-109$.

Stuehr, D.J. and Nathan, C.F. (1989) Nitric oxide. A macrophage product responsible for cytostasis and respiratory inhibition in tumor target cells. J. Exp. Med. 169, 1543-1555.

Suzumura, A., Mezitis, S.G., Gonatas, N.K. and Silberberg, D.H. (1987) 
MHC antigen expression on bulk isolated macrophage-microglia from newborn mouse brain: induction of Ia antigen expression by gammainterferon. J. Neuroimmunol. 15, 263-278.

Terenzi, F., Diaz-Guerra, M.J., Casado, M., Hortelano, S., Leoni, S. and Bosca, L. (1995) Bacterial lipopeptides induce nitric oxide synthase and promote apoptosis through nitric oxide-independent pathways in rat macrophages. J. Biol. Chem. 270, 6017-6021.

Ting, J.P. and Baldwin, A.S. (1993) Regulation of MHC gene expression. Curr. Opin. Immunol. 5, 8-16.

Ting, J.P., Shigekawa, B.L., Linthicum, D.S., Weiner, L.P. and Frelinger, J.A. (1981) Expression and synthesis of murine immune response-associated (Ia) antigens by brain cells. Proc. Natl. Acad. Sci. USA 78, $3170-3174$
Weinstein, S.L., Gold, M.R. and DeFranco, A.L. (1991) Bacterial lipopolysaccharide stimulates protein tyrosine phosphorylation in macrophages. Proc. Natl. Acad. Sci. USA 88, 4148-4152.

Wen, Z., Zhong, Z. and Darnell, Jr., J.E. (1995) Maximal activation and transcription by stat 1 and stat 3 requires both tyrosine and serine phosphorylation. Cell 82, 241-250.

Williams, K., Bar-Or, A., Ulvestad, E., Olivier, A., Antel, J.P. and Yong, V.W. (1992) Biology of adult human microglia in culture: comparisons with peripheral blood monocytes and astrocytes. J. Neuropathol. Exp. Neurol. 51, 538-549. 